Int.J. Hum. Soc. Dev. Res.

ISSN(P):2521-1439; ISSN(E):2523-4331

Volume 4, Number 2, 2020. 52-66

DOI: $10.30546 / 2523-4331.2020 .4 .2 .52$

\title{
ANTENATAL CARE SERVICE UTILIZATION AMONG WOMEN OF REPRODUCTIVE AGES IN FIXED OCCUPATION IN EDO STATE, NIGERIA
}

\author{
Michael NDISIKA, \\ University of Benin, Benin, Nigeria
}

\section{Iyobosa E. OBOBAIFO, \\ University of Benin, Benin, Nigeria}

(C) The Author(s) 2020

\section{ABSTRACT}

This study was designed to examine the utilization of antenatal care of women of reproductive age who have an active occupation in Egor Local Government Area of Edo State. The survey research design was used to elicit information from the respondents using a well-structured questionnaire. A sample of 390 women were randomly selected through the simple random sampling technique from two primary healthcare centers in Egor local government Area of Edo State. The researcher visited the health care centers while the women were with their babies for immunization and other health services. The primary data collected were analyzed using simple percentage and mean frequency while the ANOVA and independent T- test was used to analyze the hypothesis of the study. The result revealed that the respondents' utilization of antenatal care was good. Majority of the respondents responded positively to attitudinal questions on antenatal care and their perception on antenatal care was generally considered positive. The study further revealed that the majority of the women $(60 \%)$ booked late at antenatal clinic mostly in the third trimester (7-9months) of their pregnancy, this may be due to their inability to get work permits to visit the health centers as at when due. The study recommended that pregnant women should be encouraged to book at antenatal clinic early specifically in the first trimester of their pregnancy ideally before 12 weeks but no later than 16 weeks as recommended by the World Health Organization for better pregnancy outcomes.

\section{C2020.All rights reserved}

\section{ARTICLE HISTORY}

Received: 18/06/2020

Accepted:06/10/2020

Published online:30/10/2020

\section{KEYWORDS}

Utilization, Antenatal, women, Occupation, government, World Health Organization. 



\section{Introduction}

Improving maternal health is one of the World Health Organization's Millennium Development Goals (MDGs). A professional health care during child birth is one of the process indicators in assessing progress towards these goals. WHO, (2009) has recommended four strategic interventions or four pillars for safe motherhood. These include; Family planning, Antenatal care (ANC), Clean/ safe delivery and Emergency obstetric care. Some of the interventions that have been shown to be effective in detecting, treating or preventing conditions in pregnant women that might otherwise give rise to serious morbidity and mortality are: Detection and investigation of aneamia, Pregnancy induced hypertension, Treatment of severe pre-eclampsia, Screening and Prevention of infection and Diagnosis of obstructed labour. Shafqat, Fayaz, Rahim and Saima, (2015) noted that antenatal care is considered as a back bone of obstetrical services of any health care delivery system. It is considered to be important for the health of pregnant women and is the way in which maternal and feotal complications are detected and managed.

Utilization of ANC services has been identified in a number of studies as an important factor determining maternal and infant mortality. However, the use of health services is a complex behavioural phenomenon. It is affected among other factors by socio-demographic factors (such as age, occupation, education, maritalstatus, religion and income level), cultural background of the women, knowledge about antenatal care services and perception of the quality of care services provided at the health facility. For all the benefits that have been attributable to ANC, the effectiveness of antenatal care in actually reducing maternal and fatal morbidity and mortality, has never been scientifically proven and because of ethical considerations may never be proven. In a study on the determinants of maternal health services in rural India, it was found that, there is a correlation between household income and utilization of maternal health services (Sharif and Singh, 2002). It was evident that as a result of lack of productive resources for women, income earned by women had negative impact on utilization of Ante Natal Care (ANC) and Post Natal Care (PNC). A similar study comparing utilization of health services in Urban and Rural Kenya revealed that cost of health facilities deprives the poor of access to health care facilities. The study also established that income is exceeded only by distance as the most important factor influencing the utilization of health services in slums, (Ikaman, 2004). 
Health knowledge is considered as one of the key factors that enable women to be aware of their right and health status in other to seek appropriate health services. So, lack of knowledge about the ANC services could also be a major barrier to women's utilization of ANC services. Due to lack of knowledge, pregnant women are likely to have limited knowledge and experiences in seeking health care. Matua, (2004) and Jewkes, (1998) cited lack of adequate knowledge and information about pregnancy, laboratory tests results and dangers of late bookings or not attending ANC at all, as contributors to the poor utilization of ANC services. Lack of knowledge about the dangers of not seeking health care in pregnancy and delivery were major barriers to seeking health care among pregnant women in Uganda (Matua, 2004). The level of knowledge of women of child bearing age about antenatal care will help draw attention to the areas where health workers should focus on while educating women about maternal health. Also, utilization of antenatal care services is associated with improved maternal and neonatal health outcomes. This survey will help to provide data for implementation of intervention programmes to improve maternal health in the local government area of study. The survey will also provide information that the policy makers can use for planning. The reportedly high maternal mortality rate in Nigeria with antenatal care utilization being an important determinant of maternal mortality rate is a justification for carrying out this study. The aim of the study is to examine the factors that affect utilization of antenatal care services by women of child bearing age with an ongoing occupation in Egor local government area of Edo state.

\section{Problem Statement}

Data from Nigeria Demographic and Health Survey, (2013) indicated that $34 \%$ of women of reproductive ages (15-49) in Nigeria did not receive antenatal care at all. Osubor, Fatusi, and Chiwuzie, (2006) reported that among eighty-one women who delivered within a one year period in Edo state, Nigeria, only 9.9\% received antenatal care. If this trend of low antenatal care utilization persists the implications are: first, the goal of employing antenatal care as a veritable tool for the reduction and/or prevention of maternal mortality in developing countries Nigeria included, may never be achieved. Secondly, government and other stakeholders spend huge amount of money in making antenatal care services available. If such services are not utilized or underutilized, then such investment in the provision of equipments and training of personnel is wasted. One of the major aims of attaining primary health care program in developing countries including Nigeria is to improve reproductive and child health services. 
This calls for the need to identify and improve those services vital to the health of women and girls. These services include antenatal care, delivery, postnatal care and family planning. Antenatal care aims at preserving the physiological aspect of pregnancy and labour and to prevent or detect, as early as possible, all that is pathological. Antenatal care (ANC) is a key strategy to improving maternal and infant health.

However, there is need to know the level of utilization of women in occupation to antenatal care in Egor Local Government area of Edo state.

\section{Study Objectives}

1. To determine the socio-economic characteristics of women within the reproductive ages in respect to antenatal care utilization in Egor.

2. To determine the level of utilization of antenatal care service among the women of various occupations in Egor.

\section{Study Hypothesis}

Ho: There is no significant difference in the utilization of antenatal care services by women of various occupations in Egor.

Ha: There is significant difference in the utilization of antenatal care services by women of various occupations in Egor.

\section{Literature Review}

Antenatal care begins with 'history-taking' and is followed by a complete examination of the patient. Thereafter, the mother-to-be receives advice and instructions about her mode of life, diet and regular antenatal check-ups till labor sets in. The obstetric history begins with the age of the mother and includes information about the number of years since marriage, number of pregnancies, previous deliveries, abortions, pre-term labor, complications during previous pregnancies or labor, and so on. Difficulties in previous deliveries, application of forceps, caesarean births and the birth weight of former children is also important. The date of the last menstrual period and the duration and frequency of normal menstrual cycles and also the calculation of the expected date of delivery is done at this stage. 
The due day is calculated by adding nine months and seven days to the day of the last menstrual period. A general history is necessary and asked regarding the occurrence of any illness in the past - German measles, rheumatic fever, tuberculosis, and psychological disorders. A family history of diabetes mellitus or hypertension is also enquired into.

Antenatal classes are designed to educate and inform prospective parents about a range of different subjects related to pregnancy, labor and childbirth and caring for a newborn baby. The classes are not compulsory but midwives and doctors recommend attending a class, as they can be very useful, especially for first time parents. Community health workers (CHWs) and skilled attendants help women and their families become active participants in maintaining normal pregnancy and in seeking additional care when required (De graft-Johnson, Kerber, Tinker, Otchere, Narayanan, Shoo, Oluwole and Lawn, 2005), they can work together to provide antenatal care services, counseling and health education for pregnant women. Trained CHWs can provide health education on how to prepare for birth and potential complications and promote the benefits of receiving antenatal care.

The National Institute of Statistics and Economic Analysis Benin (2012), noted that the main objectives of antenatal care are: prevention and treatment of obstetric complications, preparation for emergencies, family planning, meeting nutritional, social, emotional needs for pregnant woman, including care and nutrition of the newborn. In a similar development, Linecentto, Mothebesoane-anoh, Gomez and Munjanja, (2013) noted that the goal of antenatal care is to ensure that gestational outcomes end in the birth of a healthy baby without adversely affecting the health of the mother. This is achieved by: detection and early treatment of problems and complications; prevention of complications and diseases; health promotion, preparation for childbirth and potential complications. Earlier, Lincetto et al. (2010) noted that the goal of the ANC package is to prepare for birth and parenthood as well as prevent, detect, alleviate, or manage the three types of health problems during pregnancy that affect mothers and babies:

- $\quad$ Complications of pregnancy itself

- $\quad$ Pre-existing conditions that worsen during pregnancy

- $\quad$ Effects of unhealthy lifestyles

In the vein, Adekanle and Isawumi, (2008) noted that the purpose of the specialized form of care (antenatal) is to assure that every pregnancy ends in the birth of a healthy baby with no impairment in the mother's health. 
Kadapatti and Vijayalaxmi, (2012) stated that the aim of antenatal care is to preserve the physiological aspect of pregnancy and labour and to prevent or detect, as early as possible, all that is pathological.

Meanwhile, Ekabua and Njoku, (2011) outlined the major goals of ANC as:

1) Promotion and maintenance of the physical, mental, and social health of mother and baby by providing education on nutrition, personal hygiene, and birthing process;

2) Detection and management of complications during pregnancy, whether medical, surgical, or obstetrical;

3) Development of birth preparedness and complication readiness plan;

4) Preparation of mother to breastfeed successfully, experience normal puerperium, and take good care of the child physically, psychologically and socially.

From the foregoing, it is clear that antenatal care has a major aim of improving pregnancy outcomes hence, reducing maternal child morbidity and mortality during pregnancy and in the post-partum period. Therefore, antenatal care remains one of the pillars of the safe motherhood initiative and a core strategy in the Millennium Development Goals of preventing child mortality and improving maternal health. On the importance of antenatal care Lincetto et al. (2010), argued that antenatal care improves the survival and health of babies directly by reducing stillbirths and neonatal deaths and indirectly by providing an entry point for health contacts with the woman at a key point in the continuum of care. They further argued that it provides women and their families with appropriate information and advice for a healthy pregnancy, safe childbirth, and postnatal recovery, including care of the newborn, promotion of early, exclusive breastfeeding, and assistance with deciding on future pregnancies in order to improve pregnancy outcomes.

Lastly, they opined that antenatal care indirectly saves the lives of mothers and babies by promoting and establishing good health before childbirth and the early postnatal period - the time periods of highest risk. ANC often presents the first contact opportunity for a woman to connect with health services, thus offering an entry point for integrated care, promoting healthy home practices, influencing care seeking behaviours, and linking women with pregnancy complications to a referral system.

NDHS, 2013 listed the importance of antenatal care by trained provider as follows: 
a. It enhances early detention of complication and prompt treatment (e.g, detection and treatment of sexually transmitted infections).

b. It enhances the prevention of diseases through immunization and micronutrients supplementation.

c. It enhances birth preparedness and complication readiness.

d. It also enhances health promotion and disease prevention through health messages and counseling for pregnant women.

AbouZahr and Wardlaw, (2003) noted that there are potential benefits to be derived from some of the elements of antenatal care, and these benefits may be most significant in developing countries where morbidity and mortality levels among reproductive-age women are high. Campbell and Graham, (2006) asserted that the supposed benefits of antenatal care (ANC) to babies include increased growth, reduced risk of infection and increased survival. In another development, Akanbiemu, Manuwa-Olumide, Fagbamigbe, Ayo and Adebowale, (2013) argued that benefits of antenatal care may be more effective when its services are accessed early in pregnancy.

The second and the more recent approach to antenatal care is the focused antenatal care. The focused antenatal care according to NDHS,(2013) hinges on the principle that every pregnancy is at risks of complication and that all women should therefore; receive the same basic care and monitoring for complications (WHO, 2005). Obionu, (2006) postulates some justification for focused antenatal services. These include that all pregnant women are at risk of developing complication, that more attention are given to individuals in the high risk group but the risk approach to antenatal services increase the like hood that a skilled healthcare provider will present at birth.

The World Health Organization (WHO) began promoting the new model of ANC for low-income countries, moving away from the traditional model, largely developed in the West based on the evidence from 2001 systematic review (Carroli, Rooney and Villar, 2001). The updated model is based on 'reduced but goalorientated clinic visits' consisting of (at least) four visits to a health facility during an uncomplicated pregnancy. On this note, Kinzie and Gomez, (2004) noted that this updated approach to antenatal care emphasizes quality over quantity of visits.

Focused antenatal care approach is based on evidence-based interventions that address the most prevalent health issues that affect mothers and newborns. Its major goal is to help women maintain normal pregnancies through targeted 
assessment and individualized care (Maternal Neonatal Health, 2004). The focus is on individualized care and not number of routine visits. Hence, it is aimed at not only to achieve a minimum number of 4 visits, but also the timeliness of the commencement of the visits as well as the quality and relevance of services offered during the visits. The focused antenatal care model is now advocated as against the traditional care since an evidence-based research found the practice of the traditional antenatal care based on the European models to be wasteful and misleading (Ekabua et al. 2011 \& Rooney, 1992). While a more recent systematic review has raised questions about the efficacy of focused ANC (Dowswell et al, 2010), WHO, (2011) has maintained that focused antenatal care remains the WHO's recommendation for low-income countries. On this note Villar \& Bergsjo, (1997) asserted that scarce resources in some developing countries have led many commentators to suggest that unnecessary antenatal visits should be reduced in favour of fewer, more effective visits.

Based on WHO's recommendation of four antenatal visits for women whose pregnancies are progressing normally, first visit should commence in the first trimester (ideally before 12 weeks but no later than 16weeks) while second visit should be between 24 and 28 weeks of pregnancy; the third visit is at 32 weeks; and the fourth at 36 weeks (NDHS, 2013). In addition, each visit should include care that is appropriate to the woman's overall condition and stage of pregnancy, and help her prepare for birth and care of the newborn. If problems or potential problems that will affect the pregnancy and newborn are detected, the frequency and scope of visits are increased.

The recommended focused ANC package incorporates a range of interventions. These interventions are described below:

- Immunizations against tetanus with tetanus toxoid, a stable, inexpensive vaccine that helps to prevent neonatal and maternal tetanus. Tetanus causes about 200,000 infant deaths every year and accounts for $8 \%$ of all neonatal deaths.

- $\quad$ Reduction of iron deficiency anemia through nutritional counseling and iron/foliate supplementation Iron deficiency anemia is the single most prevalent nutritional deficiency affecting pregnant women.

In endemic countries, the prevention and treatment of hookworm infection and the prevention and treatment of malaria are also important interventions to reduce non-nutritional anemia. 


\section{- $\quad$ Prevention against malaria for women living in malaria endemic zones} through the use of insecticides, treated nets, intermittent preventive treatment and effective case management of malaria illness (WHO, 2003).

- Prevention of STI/HIV/AIDS and prevention of mother to child transmission of HIV through testing and counseling, and antiretroviral prophylaxis or treatment, and infant feeding counseling and support. Mother to child transmission is the most significant source of HIV infections in

\begin{tabular}{|l|l|l|}
\hline Age of Respondents & Frequency & Percent \\
\hline
\end{tabular}

below the

age of 15 years (WHO, 2004).

\section{Methodology}

The survey research design was used to observe and describe the different variables used for the study. The study also engaged the use of primary and secondary sources of data. Primary data were collected through the use of wellstructured questionnaires titled 'Utilization of Antenatal Care Services Questionnaire (UACSQ)', and in-depth interviews while secondary sources of data involved extensive and thorough library research and examination of existing literature, archival documents in the subject areas. A number of research questions were raised in the study. Quantitative and qualitative data were generated through field surveys and at the end; the results were compared with each other through the process of triangulation. The population comprised of all women residing in the local government of study which amounted to 94,623 women, while the Yamane formula was used in selection of the sample size for administration of questionnaires. The simple random sampling technique was used to select two health centers from the nine health centers in the local government area of study. Then a total of 398 sample size was further drawn from the two health centers using the same technique. The respondents were chosen on the spot when the researcher paid a visit to the health centers with the intention of collecting data from them. The researcher kept on paying visit to the health centers at intervals until the desired number of respondents was obtained.

From the data collected, the demographic and questionnaire information of the respondents was analyzed through simple percentage and mean frequencies while the $\mathrm{T}=$ test of independence and Analysis of variance (ANOVA) was used to test the hypotheses at the 0.05 level of significance.

Data Analysis and Interpretation Table 1: Socio-Demographic Data (a) 


\begin{tabular}{|l|l|l|}
\hline $15-25$ & 78 & 20.0 \\
$26-35$ & 181 & 46.4 \\
$36-45$ & 109 & 27.9 \\
Above 45 & 22 & 5.6 \\
Total & 390 & 100.0 \\
\hline Occupation of Respondents \\
\hline Housewife & 85 & 21.8 \\
Runs small business & 189 & 48.5 \\
Formal employment & 116 & 29.7 \\
Total & 390 & 100.0 \\
\hline Yearly Income of Respondents (\#) \\
\hline Less than 60000 & 102 & 26.2 \\
60000 - 120000 & 148 & 37.9 \\
121000 - 180000 & 62 & 15.9 \\
181000 - 240000 & 23 & 5.9 \\
Above 240000 & 55 & 14.1 \\
Total & 390 & 100.0 \\
\hline Level of Education of Respondents \\
\hline Primary & 46 & 11.8 \\
Secondary & 153 & 39.2 \\
Tertiary & 191 & 49.0 \\
Total & 390 & 100.0 \\
\hline
\end{tabular}

\section{Source: Field Survey 2019}

From table 1 above, it shows that 78(20.0\%) are within 15-25 years, 181(46.4\%) are within 26-35 years, 109(27.9\%) are within 36-45 years while $22(5.6 \%)$ are above 45 years. The fact that majority of the women fall within 26-35 years may not be unconnected with their educational levels which happen to be on the high side.

By this age bracket it is expected that the women must have attained their tertiary education and already in their prime for reproduction. Occupation reveals that $102(26.2 \%)$ receive yearly income less than \#60000, 148(37.9\%) receive yearly income within $\# 60000$ to $\# 120000,62(15.9 \%)$ receive yearly income within $\# 121000$ to \#180000, 23(5.9\%) receive yearly income within \#181000 to \#240000 while $55(14.1 \%)$ receive yearly income above $\# 240000$. The fact that majority of the respondents are within the yearly income of \#60000 to \#120000 may not be unconnected with the fact that most of them run small scale businesses which can only bring relatively less yearly incomes. Level of education shows that 46(11.8\%) received primary education, 153(39.2\%) received secondary education while 191(49.0\%) received tertiary education. From this finding it is seen that most of the respondents are relatively highly educated. This may explain the high utilization of 
antenatal care as it is presumed that they education might have exposed them to the importance of antenatal care to health of mother and child.

Table 2: Description of the utilization of antenatal care by women of different occupations

\begin{tabular}{|l|l|l|l|}
\hline Occupation & N & Mean & Std. Deviation \\
\hline Housewife & 85 & 15.9176 & 2.87109 \\
runs small business & 189 & 17.0159 & 2.58571 \\
formal employment & 116 & 18.4224 & 2.78864 \\
Total & 390 & 17.1949 & 2.85159 \\
\hline
\end{tabular}

Table 2 shows a mean and standard deviation of utilization as15.91 and 2.87; 17.01 and 2.58; and 18.42 and 2.78 for housewife, runs small business and formal employment occupation.

Table 3: ANOVA of the utilization of antenatal care by women of different occupations

\begin{tabular}{|l|l|l|l|l|l|l|}
\hline Occupation & $\begin{array}{l}\text { Sum of } \\
\text { Square }\end{array}$ & Df & $\begin{array}{l}\text { Mean } \\
\text { Square }\end{array}$ & F & Sig. & Remark \\
\hline $\begin{array}{l}\text { Between } \\
\text { Group }\end{array}$ & 319.512 & 2 & 159.756 & 21.741 & .000 & \\
Within & 2843.678 & 387 & 7.348 & & & Significant \\
Group & 3163.190 & 389 & & & & \\
Total & & & & & & \\
\hline \\
$\boldsymbol{\alpha = . 0 5}$
\end{tabular}

Table 3 shows an $\mathrm{F}$ value of 21.741 and a $\mathrm{P}$ value of .000. Testing at an alpha level of .05 the $\mathrm{P}$ value is less than the alpha level, so the null hypothesis which states that "There is no significant difference in the utilization of antenatal care by women of different occupations in Egor" is rejected. Consequently, there is a significant difference in the utilization of antenatal care by women of different occupations in Egor. 
Table 4: Least Significant Difference (LSD) Multiple Comparisons of Utilization of antenatal care by women of different occupations in Egor

\begin{tabular}{|ll|l|l|l|}
\hline & & & & \\
(I) Occupation & $(\mathbf{J})$ Occupation & $\begin{array}{l}\text { Mean Difference } \\
\text { (I-J) }\end{array}$ & Std. Error & Sig. \\
\hline Housewife & runs small business & $-1.09823^{*}$ & .35401 & .002 \\
& formal employment & $-2.50477^{*}$ & .38703 & .000 \\
\hline \multirow{2}{*}{ Runs small business } & formal employment & $-1.40654^{*}$ & .31972 & .000 \\
\hline
\end{tabular}

*. The mean difference is significant at the 0.05 level.

Table 4 shows the mean difference between housewife and those who run small business as -1.09 and a $\mathrm{P}$ value of .002; between housewife and formal employment as -2.50 and a $\mathrm{P}$ value of .000 . Again, between those who run small business and formal employment as -1.40 and a $\mathrm{P}$ value of .000 . These comparisons again are significantly different since the $\mathrm{P}$ values are less than .05 . But the significant difference is in favour of formal employment occupation of women in Egor.

\section{Discussion of Findings}

This study found that there is difference in the utilization of antenatal care based on different occupations among the women. This finding again negates the stand of hypothesis four which declared that "there is no significance difference in the utilization of antenatal care by women of different residence in Egor". Women with formal employment tended to use antenatal care more than their counterparts in other occupation categories (small business and house wife). The explanation for this discrepancy could be that women in formal employment are most likely to be more economically empowered than their counterparts who either run small businesses or are full time house wives. Hence, better able to access antenatal care service because they are easily able to pay for it. The poorer the women are, the more likely fees are to affect their use of health services. In Zaria Nigeria, a study found that from free to fee-based services for obstetric care reduced admission overall, but significantly increased emergency cases. The number of maternal death rose correspondingly (Harrison, 1997). In order to improve utilization of antenatal care services, efforts to relieve poverty, and empower women economically are needed.

However, a divergent view noted that women's involvement in economic activities might create extra burden on them and reduce the time they have available for receiving such services. Hadi, Rahman, Khuram, Ahmed and Alam, (2007) in their 
study on "the inaccessibility and utilization of antenatal health care services in Balkh Province of Afghanistan", of which the utilization of antenatal care (ANC) services was differentiated by the participation of women in activities. The use of each of the ANC services was significantly lower among women who were involved in economic activities than among those not economically active. The conclusion drawn from the study was that women's involvement in economic activities might have created extra burden on them and reduced the time they had available for receiving such services.

\section{Conclusion and Recommendations}

Based on the findings of this study, first, it concluded that the respondents' knowledge and utilization of antenatal care was good as the respondents excellently demonstrated that they knew the term antenatal care, its purposes and services.Secondly that majority of the respondents $(60 \%)$ booked late at antenatal clinic mostly in the third trimester (7-9months) of their pregnancy and this negative attitude towards antenatal care may not be unconnected with the educational level of some of the respondents due to the fact that some previous studies have revealed that educational level could influence utilization of the antenatal care and the understanding of the importance of seeking health care promptly. It is therefore recommended that in order to improve utilization of antenatal care services, efforts to relieve poverty, and empower women economically are needed. Consequently, women no matter what should endeavour to engage themselves in productive ventures so as to be economically empowered. Also, antenatal care services should be made accessible to all pregnant women irrespective of their occupation at any point in time. Some pregnant mothers in the rural area may have basic knowledge of the importance of antenatal services but due to problems of inability to leave the work place to health facilities will hinder them from such services.

So, it is recommended that government should provide more qualified medical practitioners and equipments to health center in the area so that problem of inadequate health care providers and equipments in rural areas is reduced to barest minimum.

\section{Disclosure statement}

No potential conflict of interest was reported by the authors.

Contact Information.

Email address:michael@gmail.com 
References and notes:

Abou-Zahr, C., \& Wardlaw T. (2003) Antenatal care in developing countries: promises, achievements and missed opportunities: an analysis of trends, levels and differentials, 1990-2001. Geneva: World Health Organization. 1-32

Adekanle, D. A. \& Isawumi A. I. (2008): Late antenatal care booking and its predictors among pregnant women in South Western Nigeria. Online Journal of Health and Allied Sciences. 7(1): 1-6.

Akanbiemu, F. A., Manuwa-Olumide A., Fagbamigbe A. F. \& Ayo Adebowale A.S. (2013): Effect of perception and free maternal health services on antenatal care facilities utilization in selected rural and semi-urban communities of Ondo State, Nigeria. British Journal of Medicine \& Medical Research 3(3): 681-697. www.sciencedomain.org

Carroli, G., Rooney C. \& Villar J. (2001): How effective is antenatal care in preventing maternal mortality and serious morbidity? An overview of the evidence. Paediatr Perinat Epidemiol. 15: 1-42.

De graft-Johnson, J., Kerber K., Tinker A., Otchere S., Narayanan I., Shoo, R., Oluwole D. \& Lawn J.(2005). Household to hospital continuum of maternal and newborn care. ACCESS program: Baltimore.

Dowswell, T., Carroli G., Duley L., Gates S., \& Gu“ lmezoglu A. M. (2010). Alternative versus standard packages of antenatal care for low-risk pregnancy. The Cochrane Database of Systematic Reviews 10.

Ekabua, J., Ekabua K. \& Njoku C. (2011). Proposed Framework for making focused antenatal care services accessible: a review of Nigerian setting. International Scholarly Research Network. (25) 3964, 5.

Ikaman, L. D. E. (2004). Maternal health care utilization in Teso District, Kenya. African Journal of Health sciences (11): 21-32.

Jewkes, R., Vundule, C., Matorah, F. \& Jordan, L. (2001).Risk factors for teenage pregnancy among sexually black adolescents in Cape Town: a case control study. South African Medical Journal 91 (1): 73-80

Kadapatti, M. G. \& Vijayalaxmi A. H. M. (2012): Antenatal Care: The Essence of New Born Weight and Infant Development. International Journal of Scientific and Research Publications, Vol 2, Issue 10, ISSN 2250-3153

Kinzie, B. \& Gomez P. (2004). Basic maternal and newborn care: a guide for skilled providers. Balitmore.

Lincetto, O., Mothebesoane-anoh, S., Gomez P. \& Munjanja S. (2013) Antenatal Care. Opportunities for African's Newborns Int J Sci Technol Res. 2013; 2: 51-62.

Lincetto, O., Mothebesoane-anoh, S., Gomez, P. \& Munjanja, S.(2010). Antenatal Care: Opportunities for Africa's Newborns.

Maternal and Neonatal Health, (2004). focused antenatal care: planning and providing care during pregnancy. Program Brief, MNH Program Website.

Matua, A. G. (2004) Determinants of maternal choices for place of delivery in Ayiru county, Uganda. Africa Journal of Nursing and Midwifery 6 (1): 33-38.

Nigeria Demographic and Health Survey (2013). Calverton: National Population Commission and ORC Macro.

National Institute of statistics and economic analysis (Benin). (2012) Demographic and health and multiple indicators' survey EDSN-MICS-IV 2012: Final report. Cotonou: INSAE,

Nigeria Demographic and Health Survey (2008) A. NPC, Nigeria, Editor. National Population Commission and ICF Macro.

Obionu, C. N. (2006) Maternal and child health including family planning. In: Primary health care in developing countries. (2nd edition). Enugu: Delta Publications Limited; 217-268. 
Osubor, K. M., Fatusi A. O. \& Chiwuzie J. C. (2006). Maternal health seeking behaviour and associated factors in a rural Nigeria community. Maternal Child Health Journal , 10:159-169.

Rooney, C. I. F. (1992) Antenatal care and maternal health: how effective is it? Document WHO/MSM/92A, World Health Organization, Geneva, Switzerland.

Shariff, A. \& Singh G. (2002) Determinants of maternal health care utilization in India: Evidence from a recent household survey. Econ Papers RePec.

Shafqat, T., Fayaz S., Rahim R., \& Saima S. (2015). Knowledge And Awareness Regarding Antenatal Care And Delivery Among Pregnant Women. J. Med. Sci. (Peshawar, Print) Vol. 23, No. 2: 88-91

Villar, J., \& bergsj P. (1997). Scientific basis for content of routine antenatal care. Acta Obstetritics et Cannesy Scandinavica, vol 76, no 1.

World Health Organization, (2009). Pregnancy, Childbirth, Postpartum and Newborn Care. A guide for essential practice. Geneva: World Health Organization World Health Organization, (2005). Maternal mortality in 2005: estimate developed by WHO, UNICEF, UNFPA, WORLD BANK. Geneva.

World Health Organisation/United Nations International Children's Fund (2003). Antenatal care in developing countries. Promises, achievements and missed opportunities-An analysis of trends, levels and differentials, 1990- 2001. Geneva. World Health Organization. 